\title{
Peaceful berkelium
}

\author{
The first new element produced after the Second World War has led a rather peaceful life since \\ entering the period table - until it became the target of those producing superheavy elements, as
}

Andreas Trabesinger describes.

f nomenclature were transitive, element 97 would be named after an Irish bishop whose philosophical belief was that material things do not exist. But between the immaterialist George Berkeley and the element berkelium stands, of course, the fine Californian city of Berkeley (pictured), where the element was first produced in December 1949. The city became the eponym of element 97 "in a manner similar to that used in naming its chemical homologue terbium [...] whose name was derived from the town of Ytterby, Sweden, where the rare earth minerals were first found"1.

A great honour for the city? The mayor of Berkeley at the time reportedly displayed "a complete lack of interest when he was called with the glad tidings" ${ }^{2}$. There was every reason to take pride though. Berkelium was already the seventh new element discovered in which the city's University of California Radiation Laboratory (later renamed the Lawrence Berkeley National Laboratory) was critically involved. And by 1974, nine more elements would follow.

Though an effort of many, one name came to stand out in these elemental endeavours: Glenn Seaborg. A contributor to the Manhattan project, he played a central role in the first synthesis of plutonium. The procedures developed for its chemical isolation became crucial for the discovery of further transuranium elements. Elements 95 (americium) and 96 (curium) were still produced during the war, but the next step would prove tricky.

Work towards synthesizing element 97 started around Christmas 1945, but was rendered difficult by the fact that only minute amounts of target materials were available for irradiation, and those were intensely radioactive. Nevertheless, Seaborg's recently postulated actinide concept (which posits that elements 89-103 form a series of their own that mirror the lanthanides)

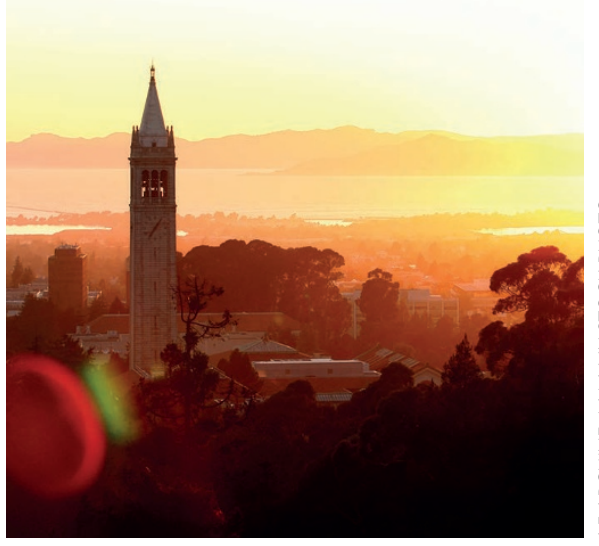

served as a helpful leitmotif. By the end of 1949, the team around Seaborg, including Albert Ghiorso and long-time collaborator and schoolday friend Stanley Thompson, had finally succeeded and obtained trace amounts of 243-berkelium by bombarding 241-americium with helium ions. The path to the new kid on the $f$-block had been tedious, so much so that Thompson and Ghiorso initially suggested assigning berkelium the chemical symbol Bm - evoking an association with 'bum' - "because it had been such a stinker in resisting identification for so long"' . In the end though, Bk was adopted.

Since its identification, berkelium led a mostly tranquil life. The element has found no practical uses, although it can be formed in nuclear detonations and in nuclear reactors. This makes understanding its chemistry relevant, in particular with a view to nuclear-waste management. Yet, studying berkelium remains a challenge. Only one isotope is available in bulk quantities: ${ }^{249} \mathrm{Bk}$, with a relatively short half-life of 330 days.

Very early tracer experiments ${ }^{3}$ had shown that berkelium has stable + III and + IV oxidation states, but further properties of berkelium have only started to transpire in the past few years. In 2016, the first singlecrystal structures were presented ${ }^{4}$, together with the finding that in $\mathrm{Bk}$ (III) compounds spin-orbit coupling leads to a mixing of the first excited state and the ground state. This gives rise to unexpected electronic properties not present in analogous lanthanide structures containing terbium. Even more recently ${ }^{5}$, a combined experimental and computational study revealed that berkelium can have stabilized +III and +IV oxidation states also under mild aqueous conditions, indicating a path to separating it from other lanthanides and actinides.

The main use of berkelium, however arguably one that wouldn't have met with Bishop Berkeley's approval - remains a distinctly material one: as the target for the synthesis of other transuranium and superheavy elements. For the production of element 117, which is currently the latest addition to the periodic table, ${ }^{249} \mathrm{Bk}$ samples were produced at the Oak Ridge National Laboratory, Tennessee (US) in a procedure that takes well over a year6. Targets were then shipped to Dubna (Russia) and later to Darmstadt (Germany), where they were bombarded with 48-calcium to synthesize element 117 . So crucial was the berkelium target in these experiments that the name of element 117 references the place where the target - not the element itself — was produced: tennessine.

ANDREAS TRABESINGER is a science writer based in Switzerland and the owner of Reinschrift Science Communication (http://www.reinschrift.ch/). He has fallen in love with Berkeley during his postdoc years there.

e-mail: at@reinschrift.ch

\footnotetext{
References

1. Thompson, S. G., Ghiorso, A. \& Seaborg, G. T. Phys. Rev. 77, 838-839 (1950).

2. Seaborg, G. T. ChemTech 8, 408-413 (1978).

3. Thompson, S. G., Cunningham, B. B. \& Seaborg, G. T. J. Am Chem. Soc. 72, 2798-2801 (1950).

4. Silver, M. A. et al. Science 353, 3762-3763 (2016).

5. Deblonde, G. J.-P. et al. Nat. Chem. 9, 843-849 (2017).

6. Hamilton, J. H., Oganessian, Y. T. \& Utyonkov, V. K. J. Phys. Conf Ser. 403, 012035 (2012).
} 